\title{
Bicomponent Hydrogels Based on Methacryloyl Derivatives of Gelatin and Mucin with Potential Wound Dressing Applications
}

\author{
ANDRADA SERAFIM ${ }^{*}$, ELENA OL ARET ${ }^{2}$, SE RGIU CECOLTAN ${ }^{1}$, LIVIA MARIA BUTAC ${ }^{3}$, BRINDUSA BALANUCA ${ }^{1,4}$, EUGENIU VASILE ${ }^{5}$, \\ MIHAELA GHICA ${ }^{6}$, IZABELA CRISTINA STANCU ${ }^{1,2 *}$ \\ 1 University Politehnica of Bucharest, Advanced Polymer Materials Group, 1-7 Gh. Polizu Str., 011061, Bucharest, Romania \\ 2 University Politehnica of Bucharest,Faculty of Medical Engineering, 1-7 Gh. Polizu Str., 011061, Bucharest, Romania; \\ 3 University Politehnica of Bucharest, Department of Bioresources and Polymers Science, 1-7 Gh. Polizu Str., 011061, Bucharest, \\ Romania \\ ${ }^{4}$ University Politehnica of Bucharest, Department of Organic Chemistry Costin Nenitescu, 1-7 Gh. Polizu Str., 011061, Bucharest, \\ Romania \\ ${ }^{5}$ University Politehnica of Bucharest, Department of Science and Engineering of Oxide Materials and Nanomaterials,1-7 Gh. \\ Polizu Str., 011061, Bucharest, Romania; \\ ${ }^{6}$ Carol Davila University of Medicine and Pharmacy, Faculty of Pharmacy, Department of Physical and Colloidal Chemistry, \\ 020956, Bucharest, Romania
}

\begin{abstract}
The present paper reports the first attempt to synthesize bicomponent hydrogels based on methacryloyl derivatives of gelatin (GelMA) and mucin (MuMA) with different compositions, with potential as wound dressings. While gelatin is widely investigated and used to fabricate scaffolds and coatings stimulating cell interactions and tissue regeneration, mucin - a macromolecule which covers the wetepithelia - remains yet under exploited as biomaterial. The influence of MuMA content on various parameters such as the affinity for aqueous media, stability in simulated physiologic media and the rheologic behavior was investigated. Also, the preliminary assessment of the drug release potential and biocompatibility were performed. The materials' water uptake capacity and rheologic behavior depend on the $\mathrm{pH}$ value of the incubation media, while their composition influences the drug release capacity and cells-scaffold interactions.
\end{abstract}

Keywords: Methacryloyl gelatin, methacryloyl mucin, network-forming polymerization, hydrogels

Skin represents the largest organ of the body and its primary role is to act as a shield between the body and the external factors. When skin is ruptured, covering the wound is necessary in order to protect the body from possible microbial attack and fluid loss [1]. Minor dermal lesions such as scratches might heal without scars, but large fullthickness defects require surgical intervention and may lead to tissue contraction and formation of unaesthetic marks.

In the early 80s' a significant breakthrough was made in the field of dermal treatments designed for large wounds, by the development of a skin substitute based on collagen and glycosaminoglycans, subsequently commercialized under the name of Integra Artificial Skin ${ }^{\circledR}$. Despite further advances in the fields of medicine and technology, and the increased availability of new relevant products, an ideal skin product for skin replacement and repair has not been yet found and autografts still represent the golden standard [1]. According to a survey performed by Selig et al. among clinicians, an ideal wound dressing should be non-adhesive to the wound bed and easy to remove, absorbent, available in a large range of sizes and should possess antimicrobial properties [2]. In addition, these materials should positively influence the regeneration of the affected tissue.

Considering the previously described features, hydrogels show great potential for such applications, especially due to their functional resemblance to the natural extracellular matrix (ECM) and their ability to absorb and retain large amounts of water without dissolving [3]. Moreover, hydrogels can easily be loaded with various drugs, such as local anesthetics, antibiotics or pain-relievers [4].
Gelatin represents a main actor in the development of hydrogels with applications in the field of soft tissue engineering due its biocompatibility, biodegradability, nontoxicity, non-immunology and low price. The use of gelatin as wound dressing has been limited due to its solubility in aqueous media, poor thermal and mechanical behavior. Gelatin's methacryloyl derivative has been obtained through the directreaction with the methacrylic anhydride, as first reported by Van Den Bulcke et al. [5], and it is currently used to obtain simulated physiological microenvironments [6-10]. Methacryloyl gelatin (GelMA) can be further polymerized similarly to a synthetic monomer, leading to biocompatible, mechanically and thermally stable, insoluble materials with tunable properties (e.g: porosity, degradability, water uptake capacity) [3].

Mucin is a high-molecular mass glycoprotein which covers the wetepithelia, its main function being to protect the organism from small particles, viruses or bacteria [11]. Its unique structure consists of a protein backbone amounting for about $20 \%$ of its total mass, on which highly glycosylated carbohydrates are radially attached $[11,12]$. This molecule seems appealing for modulating gelatin's properties. There are only a few studies regarding the use of mucin, mostly for drug-delivery applications [11,13], as biological surfactants [14-16] or anti-bacterial barrier $[12,17-19]$. To the best of our knowledge, methacryloyl mucin (MuMA) has been investigated only for sustained drug delivery applications [11], while a system formed by the GelMA and MuMA has never been synthesized before.

This paper presents the first attempt regarding the synthesis and characterization of such bicomponent systems. The aqueous media uptake capacity, stability and

\footnotetext{
* andrada.serafim@gmail.com; izabela.stancu@upb.ro
} 
rheologic behavior of the materials were correlated with their composition. Moreover, their drug release potential and biocompatibility were preliminary assessed.

\section{Experimental part}

Materials and methods

Gelatin from cold water fish skin, bovine submaxilary mucin and methacrylic anhydride were purchased from Sigma Aldrich and used without any further purification. Phosphate buffer saline (PBS) was purchased from Sigma Aldrich and prepared as indicated by the manufacturer. $\mathrm{NaOH}$ (1M aqueous solution) and $\mathrm{HCl}$ (conc. 37\%), both from Sigma-Aldrich were used in order to modify the pH of the PBS. O-phthalic aldehyde (OPA), n-butylamine, mercaptoethanol, sodium bicarbonate and ethanol were purchased from Sigma for the detection of amine groups. 1-[4-(2-Hydroxyethoxy)-phenyl]2-hydroxy-2-methyl-1-propane-1-one (Irgacure 2959, Sigma-Aldrich) was used as photo-initiator. Lidocaine (Sigma Aldrich) was used as model drug in order to assess the compositions' potential for controlled release.

Synthesis and characterization of methacyloyl derivatives

Both proteins were modified through the direct reaction with methacrylic anhydride. The modification of gelatin was performed following the protocol previously described in [3]. The obtained macromonomer was subjected to UV-VIS analysis and the degree of substitution (DS) was estimated from the quantitative determination of $-\mathrm{NH}_{2}$ groups in the raw gelatin and in GelMA respectively, using the method of primary amines detection through the reaction with OPA. The protocol is described elsewhere [20]. Briefly, solutions of both raw and modified gelatin were mixed with the relevant reagents (reagent A: $0.05 \mathrm{~L}$ borate buffer $\mathrm{pH} 10$ and $25 \times 10^{-6} \mathrm{~L}$ mercapto-ethanol and reagent B: $20 \times 10^{-3} \mathrm{~g}$ OPA dissolved in $0.01 \mathrm{~L}$ ethanol and $0.04 \mathrm{~L}$ distilled water) and the absorbance was read using a CINTRA 101 spectrometer, at a fixed wavelength of $340 \mathrm{~nm}$ at $15 \mathrm{~min}$ after the reagents were added. The values were further converted into amount of reacted $-\mathrm{NH}_{2}$ and, subsequently in DS using equation 1.

$$
D S, \%=\frac{\left(\text { initial no. of moles of }-\mathrm{NH}_{2} \text { groups }\right)-\left(\text { final no.of moles of }-\mathrm{NH}_{2} \text { groups }\right)}{\left(\text { initial no.of moles of }-\mathrm{NH}_{2} \text { groups }\right)} \times 100
$$

MuMA was obtained using a modified version of the protocol described in [11]. Briefly, an aqueous solution of mucin ( $1 \% \mathrm{w} / \mathrm{v})$ was adjusted with $\mathrm{NaOH}$ at $\mathrm{pH} 8$ and cooled on a water bath, then MA was added to a final concentration of $0.9 \%$. $\mathrm{NaOH} 5 \mathrm{M}$ was used in order to maintain the $\mathrm{pH}$ value at 8 . The reaction was kept overnight at $4^{\circ} \mathrm{C}$ under continuous stirring. Subsequently, the reaction mixture was purified using dialyses membranes (MWCO $12000-14000 \mathrm{Da}$ ) for 3 days with 3 changes of water per day. The so-obtained mixture was poured in Petri dishes and freeze-dried for $48 \mathrm{~h}$ at $-80^{\circ} \mathrm{C}$. The obtained MuMA was kept at $-20^{\circ} \mathrm{C}$ until further use. The success of the modification was proven through attenuated total reflectance Fourier transform infrared (ATR-FTIR) spectrometry using a Jasco 4200 spectrometer equipped with a Specac Golden Gate ATR device with a resolution of $4 \mathrm{~cm}^{-1}$. The spectra deconvolution was performed using OMNIC V8.2 software (ThermoFisher).

\section{Synthesis of the bicomponent systems}

Bicomponent hydrogels were obtained through the network-forming polymerization of mixtures containing GelMA and MuMA. Briefly, the modified proteins were dissolved in double distilled water (ddw) in various ratios (table 1), at room temperature, maintaining the total solid contentat 15\%. After the addition of photo-initiator (Irgacure 2959), $1 \%$ with respect to the total protein mass, the mixture were transferred in Petri dishes and subjected to polymerization for 12 minutes at $312 \mathrm{~nm}$ wavelength using UV transiluminator ECX-F26. GelMA hydrogel was synthesized as control sample.

For the investigation of the drug release potential, GelMAMuMA hydrogels were obtained in a similar manner. Lidocaine was selected as model drug and added in the polymerization precursors in a $0.5 \%$ ratio with respect to total precursor volume. The obtained lidocaine-loaded hydrogels were freeze-dried using a Martin Christ freezedrier at $-80^{\circ} \mathrm{C}$ for $24 \mathrm{~h}$.

In order to assess the biocompatibility of the synthesized materials, the polymerization precursors were synthesized as previously described and sterilized using syringe filters with pore size 0.20 microns (Milipore). The polymerization was performed in sterile Petri dishes. The obtained hydrogels were maneuvered only under the biological hood. Freeze-dried hydrogels were used.

\section{Characterization}

Evaluation of the polymerization efficiency

Gel fraction tests were performed to verify the efficiency of the network-forming polymerization. In this respect, samples with a diameter of $20 \mathrm{~mm}$ and a height of $2 \mathrm{~mm}$ of each composition were dried and weighted $\left(\mathrm{w}_{0}, \mathrm{~g}\right)$ right after synthesis and then immersed in ddw at $40^{\circ} \mathrm{C}$. After 24 $h$, the samples were removed from the incubation media, dried and weighted again $\left(w_{f}, g\right)$. The experiment was performed in triplicate. Gel fraction was estimated using equation 2:

$$
G F, \%=\frac{w_{0}}{w_{f}} \times 100
$$

Affinity for aqueous media

The affinity for physiologic simulated media of the synthesized materials was evaluated through the traditional blot and weight method. In this respect, after purification with ddw, samples (diameter $20 \mathrm{~mm}$, height 2 $\mathrm{mm}$ ) of each composition were dried, weighted and incubated in PBS at physiological temperature. The samples were removed from the incubation media and weighted until equilibrium was reached. Considering that

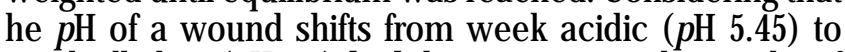
week alkaline ( $p H$ 8.9) [21] the aqueous media uptake of the synthesized composition was investigated in PBS with various $p H$ values $(5,7.4$ and 9$)$. The experiment was performed in triplicate. The equilibrium water content was evaluated using equation 3 :

$$
E W C, \%=\frac{w_{\max }-w_{0}}{w_{\max }} \times 100
$$

where $w_{\text {max }}$ is the maximum weight of the swollen gel sample after equilibrium was reached and $w$ is the initial weight of dry gel samples submitted to the test. 
Investigation of the rheologic behavior

A rheological characterization was performed in order to assess the influence of the GelMA: MuMA ratio on the elasticity of the synthesized hydrogels. To this end, samples (diameter $-20 \mathrm{~mm}$, height $-2 \mathrm{~mm}$ ) hydrated to equilibrium in incubation media with different $\mathrm{pH}$ values $(5,7.4,9)$ were subjected to dynamic oscillatory measurements. The tests were performed using a Kinexus Pro rheometer equipped with Peltier element and a plate-plate geometry (upper plate with a diameter of $20 \mathrm{~mm}$ ), at a pre-established temperature of $37^{\circ} \mathrm{C}$. Dehydration was prevented by using a solvent trap. In a first step, amplitude sweep tests were performed in order to establish the linear viscous region (LVR) of the compositions. In this respect, the samples were subjected to an increasing oscillatory stress $\left(10^{-1} \div 10^{2}\right.$ $\mathrm{Pa}$ ) while temperature and frequency are kept constant $\left(37^{\circ} \mathrm{C}, 1 \mathrm{~Hz}\right)$. Subsequently, frequency sweep tests were performed keeping the oscillatory deformation constant, at a stress value within LVR. The frequency was gradually decreased from 10 to $0.1 \mathrm{~Hz}$. The elasticity modulus ( $\mathrm{G}^{\prime}$, $\mathrm{Pa}$ ) was plotted in logarithmic scale.

\section{Stability in physiologic simulated environments}

The stability of the synthesized materials was assessed using the gravimetric method. In this respect, samples (diameter $20 \mathrm{~mm}$, height $2 \mathrm{~mm}$ ) of each composition were weighted and incubated in synthetic simulated media with different $\mathrm{pH}$ values $(5,7.4$ and 9$)$. The samples were removed from the incubation media, thoroughly washed with ddw, dried and weighted. The remaining mass of the scaffolds was estimated using equation 4:

$$
R M, \%=\frac{w_{t}}{w_{0}} \times 100
$$

where $w_{t}$ represents the remaining weight of the scaffold after incubation of and $w_{0}$ is the initial weight of dry gel samples submitted to the test.

\section{Drug release profile}

Local anesthetics are often used in numbing the pain when treating skin wounds, for both superficial and deep wounds [22]. In this study, lidocaine was selected as model drug in order to determine the release capacity of GelMAMuMA hydrogels. The synthesized lidocaine-loaded scaffolds (diameter $30 \mathrm{~mm}$, height $5 \mathrm{~mm}$ ) were tested using a sandwich device adapted to a dissolution equipment (Essa Dissolver) using phosphate buffer solution (PBS) as release media. In brief, at predefined time intervals during $12 \mathrm{~h}$ of experiments, samples of 5 $\mathrm{mL}$ were removed from the release media (PBS, $\mathrm{pH} 7.4$, $37^{\circ} \mathrm{C}$ ) and replaced with $5 \mathrm{~mL}$ of PBS preheated at $37^{\circ} \mathrm{C}$. The absorbance of the removed media was determined using a UV-Vis spectrophotometer (Perkin Elmer UV-Vis Spectrophotometer) at a fixed wavelength of $263 \mathrm{~nm}$. The amount of released lidocaine was calculated from the calibration curve obtained using lidocaine solutions of known concentrations. To establish the kinetic model of the released lidocaine the power low described by equation 5 was used:

$$
\frac{m_{t}}{m_{\infty}}=k \times t^{n}
$$

where: $\frac{m_{t}}{m_{\infty}}$ is the fractional release of drug at time $t, k$ represents the kinetic constantand $n$ represents the release exponent.

\section{Cell culture}

\section{Cell seeding}

Five freeze-dried samples from each composition were incubate in Dulbecco's Modified Eagle Medium (DMEM) supplemented with $10 \%$ fetal bovine (FBS) and penicillinstreptomycin for an hour. L929 fibroblasts were seeded at a concentration of $100000 \mathrm{celll} / \mathrm{ml}$ and incubated at $37^{\circ} \mathrm{C}$ in a humidified atmosphere with $5 \% \mathrm{CO}_{2}$ for 24 hours in flat-bottom 96- well culture plates.

\section{Cell viability}

The MTT assay (3-[4,5-dimethylthiazol-2-yl]-2,5diphenyl tetrazolium bromide - Sigma Aldrich) was performed to investigate cell viability. Non-adherent cells were removed from wells. MTT was added to a concentration of $0.5 \mathrm{mg} / \mathrm{mL}$ and cells were incubated for 4 hours at $37^{\circ} \mathrm{C}$. After this time, media was removed and it was added $150 \mathrm{~mL}$ per well of dimethylsulfoxide and cells were incubated for one hour. The media was transferred to a new plate and absorbance at $\lambda=580 \mathrm{~nm}$ was measured on a Tecan Infinite M200 PRO microplate reader. The positive control was the plastic well of the tissue culture plate (TCP).

\section{Scanning electron microscopy}

Cells morphology was investigated through Scanning Electron Microscopy (SEM) using a Quanta Inspect F SEM device equipped with a field emission gun (FEG) with 1.2 $\mathrm{nm}$ resolution. The scaffolds were coated with a thin layer of gold before analysis.

\section{Results and discussions}

\section{The synthesis of the methacryloyl derivatives}

A direct reaction of gelatin with the methacrylic anhydride allows the substitution of primary amines of the protein with polymerizable double bonds (fig. 1). The modification of gelatin and the characterization of the methacryloyl derivatives were previously reported by our group in $[3,20]$ and will not be detailed here. Following the same protocol, the DS, \% of the synthesized GelMA was computed using equation (1) showing that $64 \%$ of the $\mathrm{NH}_{2}$ groups were replaced with $\mathrm{C}=\mathrm{C}$ double bonds.

Mucin has a complex structure with a protein core on which a large number of glycosylated carbohydrates, accounting for approximately $80 \%$ of its total mass, are radially attached [23]. The bottlebrush-like structure of mucin leads to a greater exposure of the -OH groups, while the $-\mathrm{NH}_{2}$ are hindered by the carbohydrates chains. In mucin, the reaction with the methacrylic anhydride occurs mostly at the $-\mathrm{OH}$ groups on the carbohydrate side chains

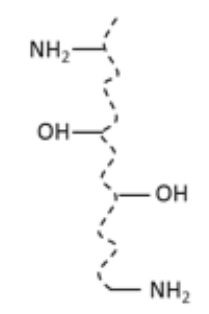

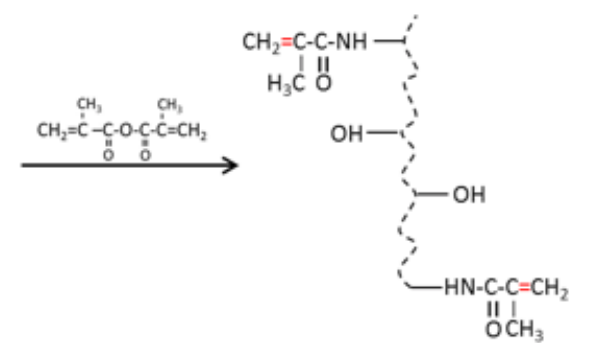

http://www.revmaterialeplastice.ro
Fig. 1. Schematic representation of the synthesis of GelMA 

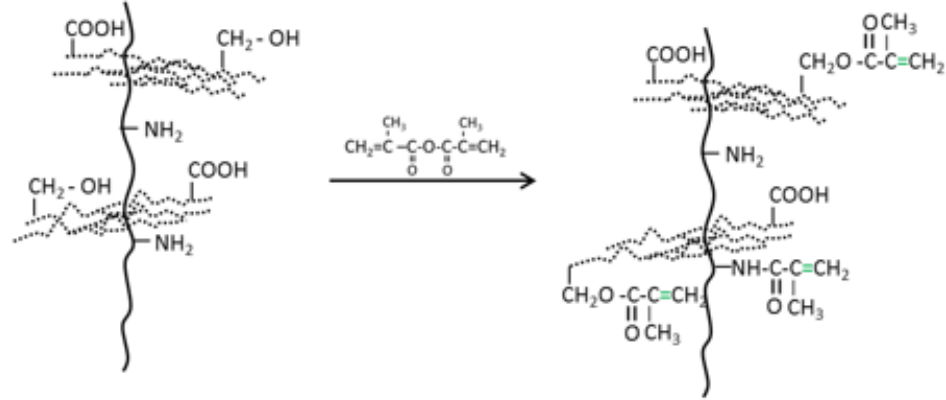

(fig. 2). Aspects regarding the reactivity of $-\mathrm{OH}$ and $-\mathrm{NH}_{2}$ groups in the reaction with the methacrylic anhydride were largely discussed elsewhere, for gelatin as substrate [24]. Yue etal. found that the polymerizable double bonds formed by the substitution of $-\mathrm{OH}$ groups represent less than $10 \%$ of all methacryloyl substitutions in gelatin and, accordingly, can be neglected [24]. However, the high amount of -OH groups in mucin and their convenient exposure for the reaction with the anhydride render the hydroxyls acylation more likely with respect to the reaction at free $-\mathrm{NH}_{2}$.

The modification of mucin was assessed through ATRFTIR (representative spectra presented in fig. 3). The spectra registered for both native mucin and MuMA showed the characteristic protein signals for amide II (around 1548 $\mathrm{cm}^{-1}$ ) and amide I (around $1655 \mathrm{~cm}^{-1}$ ). The methacryloyl derivative - MuMA - presents an additional shoulder on the amide I peak, at $1711 \mathrm{~cm}^{-1}$, assigned to the carbonyl bond of methacrylate. In order to achieve a better view of the characteristic vibrations of the methacryloyl derivative complex structure, a deconvolution of the MuMA spectrum was performed in the $1450-1750 \mathrm{~cm}^{-1}$ domain (inset in fig. 3) and the results are interpreted as follow: (1) the broad signal around $1636 \mathrm{~cm}^{-1}$ showed by the MuMA FTIR spectrum was split in two distinct peaks: $1632 \mathrm{~cm}^{-1}$ characteristic for the $\mathrm{C}=\mathrm{C}$ bonds from methacrylic groups grafted on the mucin structure and $1658 \mathrm{~cm}^{-1}$ assigned to the amide I; (2) the additional shoulder at $1711 \mathrm{~cm}^{-1}$ is present in the deconvoluted spectrum as a distinct peak and it is attributed to the carbonyl bond resulted from the modification with the methacrylic anhydride [11,25].

\section{The synthesis of the bicomponent hydrogels}

The resulted methacryloyl derivatives were used to synthesize bicomponent hydrogels with increasing MuMA content. Considering the complexity of both GelMA and MuMA structures, it is expected that the resulted hydrogels would present an elaborate structure, presenting simultaneously domains of GelMA-GelMA (domain (1) in

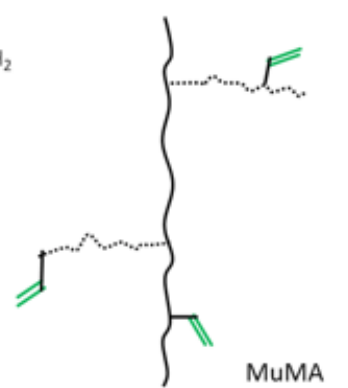

Fig. 2. Schematic representation of the synthesis of MuMA

fig. 4), MuMA-MuMA (domain (2) in fig. 4) and GelMAMuMA (domain (3) in fig. 4).

In addition to the bicomponent systems, GelMA control sample was synthesized. All synthesized systems, when hydrated, appear to be soft, elastic, transparent, varying from yellowish - in the case of the GelMA rich systems, to whitish in the case of MuMA rich systems.

\section{Evaluation of the polymerization efficiency}

The efficiency of the network-forming polymerization was assessed through a gel fraction study, the potentially unreacted precursors being extracted through incubation in $\mathrm{ddw}$, at $40^{\circ} \mathrm{C}$. Following gravimetric measurements of the dried samples before and after extraction, the gel fraction values were computed using equation 2 and the results are displayed in table 1. The obtained results, ranging from $98.00 \pm 1.43$ (S1) to $99.49 \pm 0.43$ (S2) indicate that the network-forming polymerization process was successful and the resulted materials are insoluble in water.

\section{Affinity for simulated physiologic media}

The capacity of wound dressings to uptake large amounts of physiologic fluids is essential, since the presence of exudate on the wound bed leads to biofilm formation and subsequently to infection. Considering the $\mathrm{pH}$ shift from week acidic to week alkaline during the

\section{Table 1}

THE FEED RATIO OF THE BIOCOMPONENT GEIMA-MUMA SYSTEMS; GEL FRACTION VALUES OF THE SYNTHESIZED COMPOSITIONS

\begin{tabular}{|c|c|c|}
\hline Sample & $\begin{array}{c}\text { GelMA:MuMA } \\
\text { feed ratio (wt/wt) }\end{array}$ & GF, \% \\
\hline S0 & $1: 0$ & $98.56 \pm 1.12$ \\
\hline S1 & $1000: 1$ & $98.00 \pm 1.43$ \\
\hline S2 & $100: 1$ & $99.49 \pm 0.43$ \\
\hline S3 & $50: 1$ & $99.01 \pm 0.71$ \\
\hline S4 & $25: 1$ & $97.18 \pm 2.11$ \\
\hline
\end{tabular}

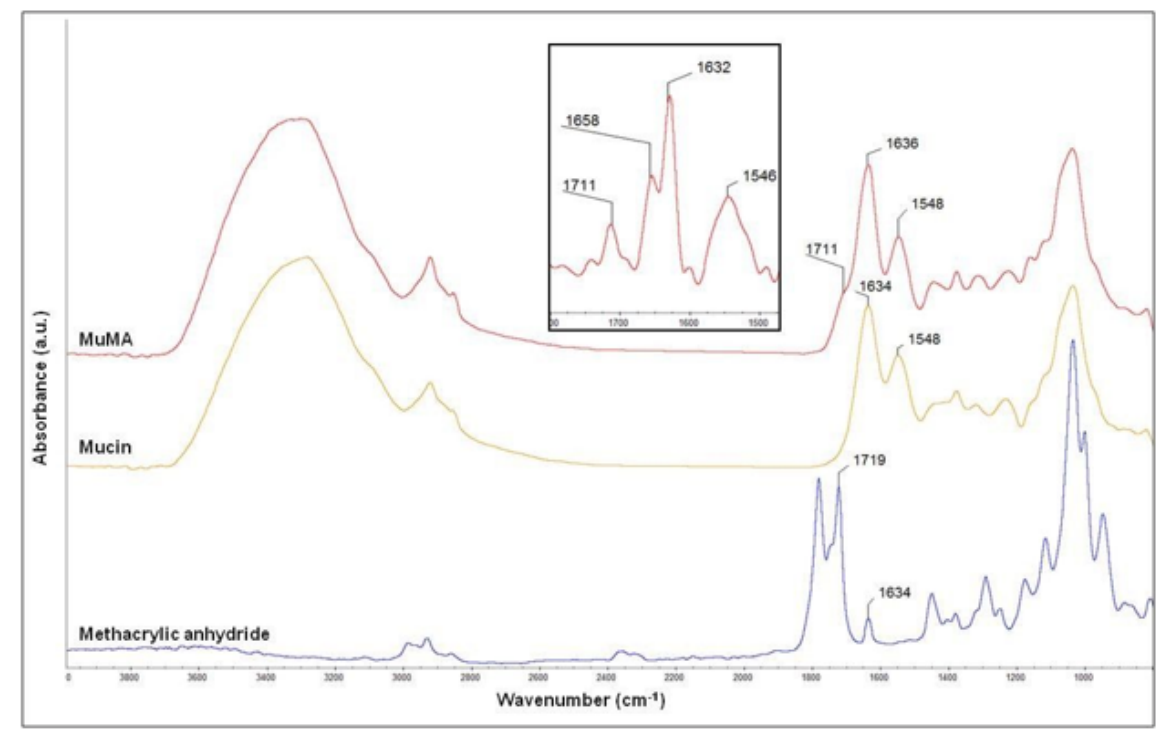

Fig. 3. ATR-FTIR spectra registered for MuMA (red), native mucin (yellow) and methacrylic anhydride (blue). Inset deconvolution in the $1450-1750 \mathrm{~cm}^{-1}$ wavenumber interval 


\begin{tabular}{|c|c|c|c|}
\hline Sample & EWC [\%], pH = 5 & EWC [\%], $\mathbf{~ H ~ = ~ 7 . 4 ~}$ & EWC [\%], pH =9 \\
\hline S0 & $85.55 \pm 0.24$ & $85.95 \pm 0.25$ & $89.79 \pm 0.24$ \\
\hline S1 & $85.82 \pm 0.40$ & $86.11 \pm 0.31$ & $90.14 \pm 0.17$ \\
\hline S2 & $85.28 \pm 0.71$ & $86.15 \pm 0.26$ & $90.12 \pm 0.21$ \\
\hline S3 & $85.42 \pm 0.73$ & $86.99 \pm 0.29$ & $90.09 \pm 0.14$ \\
\hline S4 & $85.87 \pm 0.03$ & $86.52 \pm 0.23$ & $89.48 \pm 0.43$ \\
\hline
\end{tabular}

Table 2

THE AFFINITY FOR SIMULATED PHYSIOLOGIC MEDIA OF THE SYNTHESIZED COMPOSITIONS

(SO $\div$ S4) healing stages of a wound, the ability of the synthesized hydrogels to uptake aqueous media was investigated at pH 5, 7.4 and 9.

The results, computed using equation 3 , showed that the value of the EWC of the bicomponent systems is similar to the one of the control sample, indicating that the presence of MuMA in the bicomponent composition has no significant influence in the materials' aqueous media uptake capacity. The results show that the total amount of water in all samples exceeds $85 \%$ regardless of the $\mathrm{pH}$ of the incubation media (table 2). The differences between the results computed for the samples incubated in acid media when compared to the ones of samples incubated in neutral media are extremely small; for example, the EWC of the sample with the highest content of MuMA (S4) slightly decreased from $85.87 \pm 0.03 \%$ at $p H 5$ to $86.52 \pm$ 0.23 at $p \mathrm{H} 7.4$, while the GelMA control sample (SO) showed almost no difference (from $85.55 \pm 0.24$ at $p H 5$ to 85.95 \pm 0.25 at $p H$ 7.4). However, when incubated in alkaline media, all samples show a higher EWC. Also, the addition of a small amount of MuMA leads to a slightly increased EWC (from $89.79 \pm 0.24 \%$ for S0 to $90.14 \pm 0.17 \%$ for S1), indicating that the presence of negatively charged ions in the incubation media leads to a better exposure of the hydrophilic domains.

\section{Rheologic behavior}

As in the case of the previously described investigation, the rheological behavior of the synthesized materials was assessed using fully hydrated samples in acidic, neutral and alkaline media, respectively. All tested samples showed an elastic behavior, the elastic modulus $\left(G^{\prime}\right)$ dominating over the loss modulus $\left(G^{\prime \prime}\right)$, indicating a response characteristic for crosslinked hydrogels. Also, all samples showed stability in the investigated frequency range (fig. 4).

Gelatin is a collagen-derived protein consisting of heterogeneous mixture of polypeptides. Upon modification, most the $-\mathrm{NH}_{2}$ groups were modified, while the $-\mathrm{COOH}$ remain unaltered. GelMA control sample (SO) behaves roughly in the same manner in acidic and neutral media ( $\mathrm{G}^{\prime}$ at $p \mathrm{H} 5$ is $188 \mathrm{E} \mathrm{kPa}$; $\mathrm{G}^{\prime}$ at $p \mathrm{H} 7.4$ is $155 \mathrm{E} \mathrm{kPa}$ ) due to the small amount of unmodified $-\mathrm{NH}_{2}$ groups, which are ionized. At $p \mathrm{H}$ 9, the - $\mathrm{COOH}$ groups are ionized, leading to a higher $\mathrm{G}^{\prime}(316 \mathrm{kPa})$ and thus to a more rigid network.

At $p \mathrm{H} \mathrm{5}$, the lower values of $\mathrm{G}^{\prime}$ for the GelMA-MuMA bicomponent hydrogels (S1 $\div$ S4) when compared to the control GelMA sample are probably due to the partial occlusion of the unmodified $-\mathrm{NH}_{2}$ groups in a dense netw ork, leading to a less probable, lower ionization.

As in the case of GelMA control sample, the bicomponent systems present after incubation in alkaline media an increase of the $G^{\prime}$ value, also explained by the ionization of the $-\mathrm{COOH}$ groups. However, the increase is much higher in the case of bicomponent systems (e.g. G' for S4 in pH 5 is $7.47 \mathrm{kPa}$; G' for S4 in pH 9 is $354 \mathrm{kPa}$ ). The - $\mathrm{COOH}$ groups of MuMA are positioned on the glycosylated side chains, much more exposed to ionization then the $\mathrm{COOH}$ groups in gelatin which are embedded in the coiled structure.

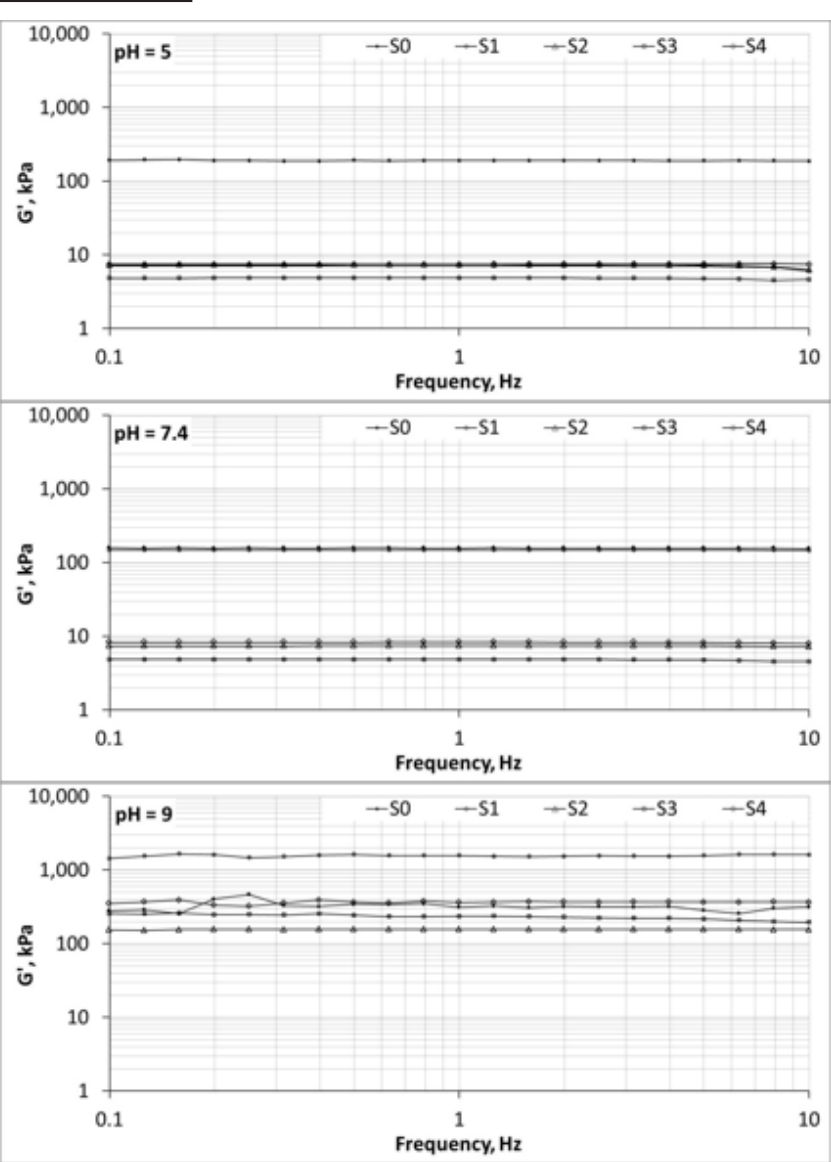

Fig. 4. The rheological behavior of fully hydrated samples in acidic, neutral and alkaline incubation media

Stability in physiologic simulated environments

The stability of the synthesized materials in physiologic simulated environments was investigated for a period of 28 days by monitoring the mass loss during incubation in media with various $\mathrm{pH}$ values: $5,7.4$ and 9 respectively. The degradation was calculated using equation 4 and expressed as remaining mass (RM, \%) of the initial mass of the samples. As depicted in figure 5 , no significant differences were registered between the synthesized materials, all compositions showing good stability, with RM values of over $85 \%$, regardless of the incubation media.

\section{Drug release profile}

The kinetic profiles registered for the synthesized compositions indicated a typical biphasic drug release, with a lidocaine burst release effect in the first 60 minutes, ensuring a rapid pain diminution, followed by a prolonged release over next 11 hours of experiments which provides a local anesthetic effect. The drug percentages released in the first stage vary between $20.41 \%$ (SO), and $27.65 \%$ (S1) respectively. As depicted in figure 6, all hydrogels release over $50 \%$ of the total drug $(50.8 \%$ (SO) $\div 64.55 \%$ (S1)).

The kinetic profiles indicated that the amount of released drug depends on the composition of the tested formulation. Hence, an increase of MuMA content determines a decrease of released lidocaine. Equation 5 was used in order to establish the lidocaine release mechanism from the synthesized hydrogels. The kinetic parameters and the 

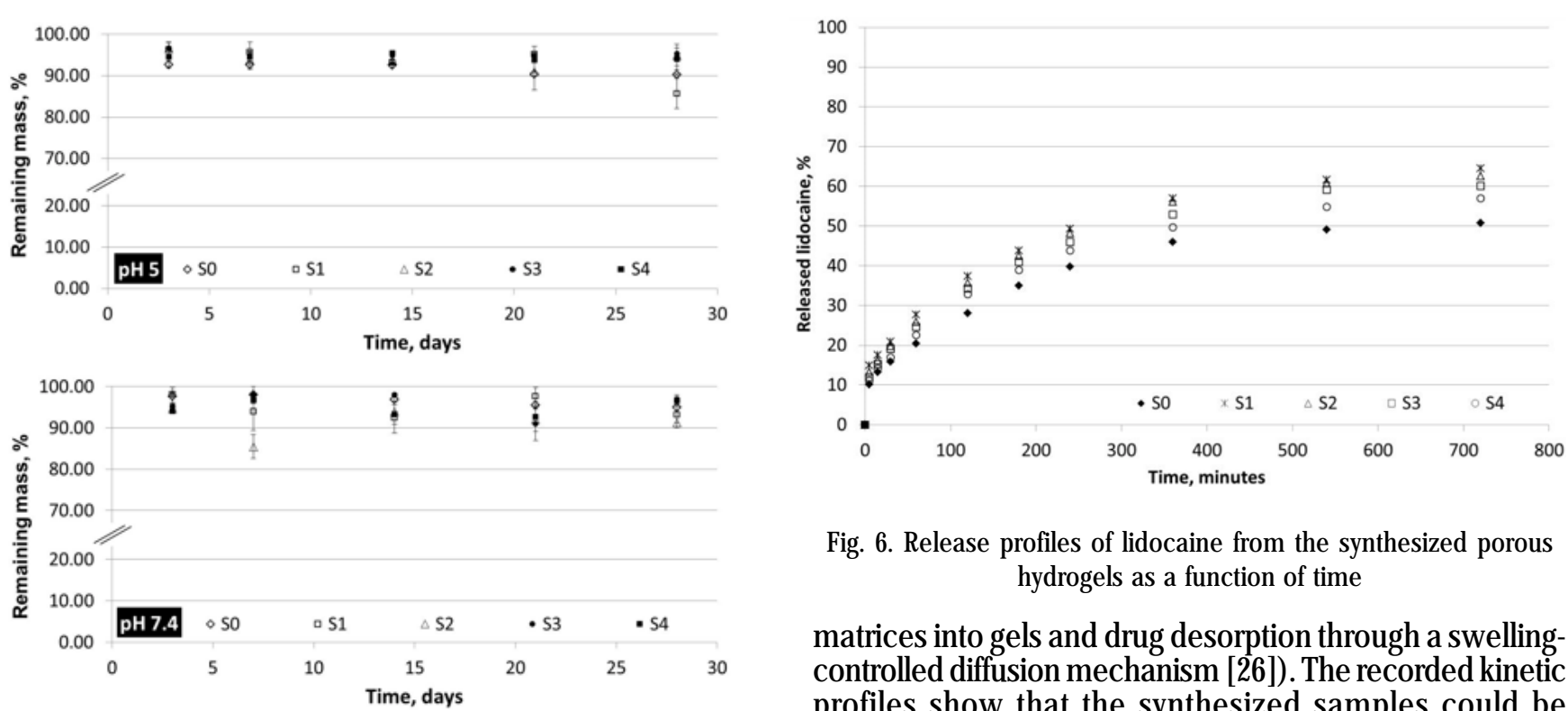

Fig. 6. Release profiles of lidocaine from the synthesized porous hydrogels as a function of time

matrices into gels and drug desorption through a swellingcontrolled diffusion mechanism [26]). The recorded kinetic profiles show that the synthesized samples could be promising carriers for drug delivery systems with potential use in skin treatment.

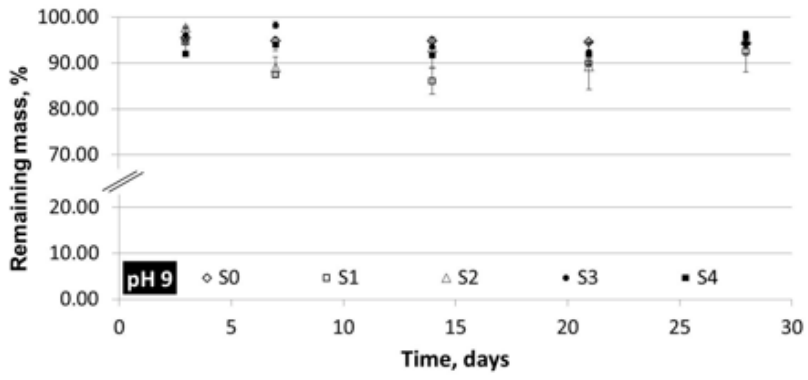

\section{Cell culture}

Both gelatin and GelMA are well investigated materials for tissue engineering applications and were often used in order to induce cell adherence in various systems $[3,6,10,11,25,27,28]$. The biocompatibility of the synthesized materials was evaluated in terms of cell viability using freeze-dried scaffolds. MTT assay was used in order to obtain quantitative data; tissue culture plate (TCP) was used as positive control. The synthesized bicomponent materials showed that increasing the MuMA content leads to a higher viability of the L929 (e.g.: the computed value for S1 was of $0.47 \pm 0.02$, while the value calculated for $\mathrm{S} 4$ was of $0.53 \pm 0.05$ ) (fig. 7).

Morphology at $24 \mathrm{~h}$ post-seeding was investigated through SEM. The registered micrographs confirmed the

Table 3

THE LIDOCAINE RELEASED PERCENTAGE; THE KINETIC PARAMETERS AND THE CORRELATION COEFFICIENT SPECIFIC FOR THE POWER LAW KINETIC MODEL; THE CORRELATION COEFFICIENT FOR THE HIGUCHI MODEL

\begin{tabular}{|c|c|c|c|c|c|}
\hline Samples & $\mathbf{k}, \mathbf{1} / \mathbf{m i n}^{\mathbf{n}}$ & $\begin{array}{c}\text { Release } \\
\text { exponent }\end{array}$ & $\begin{array}{c}\text { Correlation } \\
\text { coefficient } \\
\text { Power law model }\end{array}$ & $\begin{array}{c}\text { Correlation } \\
\text { coefficient } \\
\text { Higuchi model }\end{array}$ & $\begin{array}{c}\text { Drug } \\
\text { released (\%) }\end{array}$ \\
\hline S0 & 0,076 & 0,332 & 0,9952 & 0.9794 & 66.55 \\
\hline S1 & 0,068 & 0,345 & 0,9940 & 0.9801 & 62.57 \\
\hline S2 & 0,063 & 0,350 & 0,9946 & 0.9816 & 60.08 \\
\hline S3 & 0,058 & 0,353 & 0,9937 & 0.9809 & 56.95 \\
\hline S4 & 0,054 & 0,350 & 0,9924 & 0.9792 & 50.79 \\
\hline
\end{tabular}

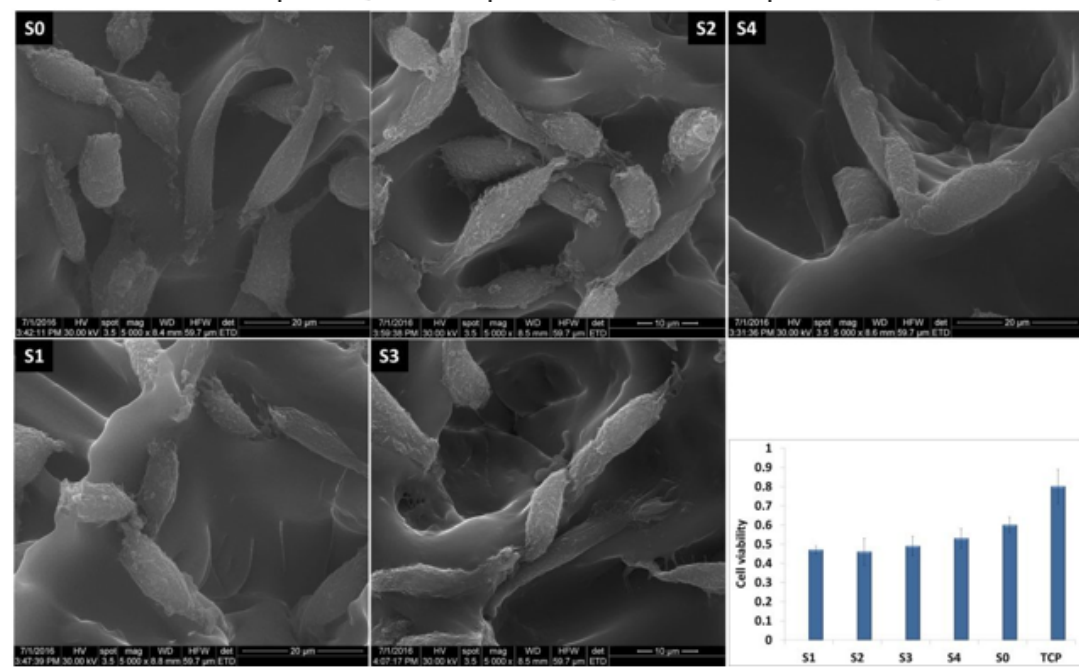

Fig. 7. Micrographs presenting the morphology of adhered cells at $24 \mathrm{~h}$ postseeding (SEM); cells viability evaluated through MTT assay 
good adherence of the L929 cells on all the synthesized materials. Elongated cells, well adhered, in intimate contact with the scaffolds can be observed on all materials (figure 7), indicating that the substrates promote cell adhesion. Also, it can be noticed that using a freeze-dried scaffold allows the cells to enter inside the pores.

\section{Conclusions}

The aim of the present study was to describe the synthesis and preliminary characterization of bicomponent hydrogels based on two natural-synthetic macromolecules. In this respect, gelatin and mucin were successfully modified through the direct reaction with methacrylic anhydride, leading to GelMA and MuMA, respectively. Subsequently, bicomponent hybrid GelMAMuMA systems with increased MuMA content were synthesized and characterized. The obtained materials showed good stability in aqueous media with $\mathrm{pH}$ ranging from week acidic to week alkaline, maintaining over $85 \%$ of their initial weight at the end of the 28 days test. The aqueous media uptake capacity was also investigated at different $p H$ values $(5,7.4$, and 9$)$ the tests showing that the highest values for the EWC were registered at $\mathrm{pH} 9$. The rheology tests showed that all compositions show elastic behavior with $\mathrm{G}^{\prime}$ dominating over $\mathrm{G}$, regardless of the $\mathrm{pH}$ of the incubation media. With the aim of correlating the controlled drug delivery ability with the hydrogels' composition, the kinetic profile of lidocaine release was analyzed for $12 \mathrm{~h}$. The performed tests showed that the addition of MuMA leads to an increase of the released amount of drug; however, increasing the amount of MuMA leads to a decrease of the released lidocaine. The SEM micrographs registered for the scaffolds seeded with fibroblasts cells showed that all compositions promote cell adhesion.

The results of this research provide a framework for the exploration of MuMA in the synthesis of hydrogel-based compositions with biomedical applications. Although the results showed that the addition of MuMa does not have a significant influence on the degradation, water uptake capacity or rheologic behavior of the bicomponent materials, the drug delivery capacity and cell adherence are improved by the addition of a small amount of MuMA (the best results being registered for the ratio GelMA:MuMA=1000:1). However, the authors believe that further studies are required in order to better control the properties of the protein derivatives and obtain the best possible combination for tissue engineering constructs.

Acknowledgements: This work has been funded with the financial support from the project 133 PED/2017, BioWall.

\section{References}

1. VENTRE M., NETTI P.A., URCIUOLO F., AMBROSIO L, Strategies in Regenerative Medicine, ed. Springer-Verlag, SANTIN M, New York, 2009, p. 15-54

2. SELIG H.F., LUMENTA D.B., GIRETZLEHNER M., JESCHKE M.G., UPTON D., KAMOLZ L.P., Burns, 38 (7), 2012, p.960
3. SERAFIM A., TUCUREANU C., PETRE D.G., DRAGUSIN D.M., SALAGEANU A., VAN VLIERBERGHE S., DUBRUEL P., STANCU I. C., New J Chem, 38(7), 2014, p.3112

4. PAWAR H.V., TETTEH J., BOATENG J.S., Colloids Surf., B., 102, 2016, p.102.

5. VAN DEN BULCKE A.I., BOGDANOV B., DE ROOZE N., SCHACHT E.H, CORNELISSEN M., BERGHMANS H., Biomacromolecules, 1, 2000, p. 31

6. ZHAO X, LANG Q, YILDIRIMER L., LIN Z.Y., CUI W., ANNABI N, NG K.W., DOKMECI M. R, GHAEMMAGHAMI A.M., KHADEMHOSSEINI A., Adv HealthC Mater. 5(1), 2016, p.108-18.

7. VAN VLIERBERGHE S., DUBRUEL P., LIPPENS E., MASSCHAELE B., VAN HOOREBEKE L., CORNELISSEN M., UNGER P R., KIRKPATRICK C.J ., SCHACHT E., J Mater Sci Mater Med., 19(4), 2008, p.1459.

8. DUBRUEL P., UNGER P R., VAN VLIERBERGHE S., CNUDDE V., JACOBS P.J., SCHACHT E., KIRKPATRICK C.J., Biomacromolecules, 8(2), 2007, p. 338

9. HOCH E., SCHUH C., HIRTH T., TOVAR G.E, BORCHERS K., J Mater Sci Mater Med., 23(11), 2012, p.2607.

10 .STANCU I.C, LUNGU A., DRAGUSIN D.M., VASILE E., DAMIAN C., IOVU H., Soft Mater., 11(4), 2013, p. 384

11. DUFFY C.V., DAVID L., CROUZIER T., Acta Biomater., 20, 2015, p. 51.

12. BANSIL R., CELLI J.P., HARDCASTLE J.M., TURNER B.S., Front Immunol., 4(OCT), 2013, p. 1.

13. OFOKANSI K.C., ADIKWU M.U., OKORE V.C., Drug Dev Ind Pharm., 33(6), 2007, p. 691.

14. SHI L., CALDWELL K.D., J Colloid Interface Sci., 224(2), 2000, p. 372.

15. SHI L., ARDEHALI R., CALDWELL K.D., VALINT P., Colloids Surfaces B Biointerfaces., 17(4), 2000, p. 229.

16. JANAIRO R.R.R., ZHU Y., CHEN T., SONG L., Tissue Eng Part A., 20(1-2), 2014, p.285.

17. CALDARA M., FRIEDLANDER R.S., KAVANAUGH N.L., AIZENBERG J., FOSTER K.R., RIBBECK K., Curr Biol. 22(24), 2012, p. 2325.

18. CORFIELD A.P., Biochim Biophys Acta - Gen Subj., 1850(1), 2015, p. 236 .

19. LI L.D., CROUZIER T., SARKAR A., DUNPHY L., HAN J., RIBBECK K., Biophys J., 105(6), 2013 p.1357.

20. SERAFIM A., DRAGUSIN D.M., BUTAC L.M., VASILESCU D.S., DUBRUEL P., STANCU I.C., UPB Sci Bull Ser B Chem Mater Sci., 75(2), 2013 , p. 3.

21.MILNE S.D., CONNOLLY P., J Wound Care, 23(2), 2014, p.53.

22.DRUCKER M., CARDENASE., ARIZTI P., VALENZUELA A., GAMBOA

A., World J Surg. 22(4), 1998, p. 394.

23. CELLI I .P., TURNER B.S., AFDHAL N.H., EWOLDT R.H., MCKINLEY G.H., BANSIL R., ERRAMILLI S., Biomacromolecules, 8(5), 2007, p.1580.

24. YUE K., LI X., SCHROBBACK K., SHEIKHI A., ANNABI N., LEIJTEN J., ZHANG W., ZHANG Y.S., HUTMACHER D.W., KLEIN T.J ., KHADEMHOSSEINI A., Biomaterials, 139, 2017, p. 163.

25. CHIU H.C., LIN Y.F., HUNG S.H., Macromolecules, 35(13), 2002, p. 5235.

26. LEE P.I., J Control Release, 2, 1985, p. 277.

27. YUE K., TRUJILLO-DE SANTIAGO G., ALVAREZ M.M., Biomaterials, 73, 2015, p. 254.

28. SERAFIM A., CECOLTAN S., LUNGU A., VASILE E., IOVU H., STANCU I.C., RSC Adv. 5(116), 2015, p. 95467. 